\title{
Wind of change in neuroscientific information
}

This issue marks the end of a decade of careful supervision of this Journal by Professor David Marsden. We all owe him and his staff, Kenneth Till, Avril Elles-Hill, Irene Mallinson, June Maxwell, Professor Graham Teasdale and the editorial committee, a debt and take this opportunity of expressing our gratitude. The incoming editor faces the prospect of assessing several hundred manuscripts each year, a daunting figure which is increasing each year and threatens to become thousands. In order to cope with this influx without retiring from clinical practice and yet make sure that each paper receives fair consideration I have adopted Caesar's policy of dividing and perhaps not ruling but at least leading. Professor Graham Teasdale has agreed to continue in post as associate editor, Dr Michael O'Brien, one of my colleagues at Guy's Hospital, becomes deputy editor and Dr John Pearce book review editor. The post of technical editor will be taken by Madeline Harrington and the editorial office has now moved from BMA House to the Guy's Campus of the United Medical and Dental Schools of Guy's and St Thomas's Hospitals under the charge of our new editorial assistant Suzanne Miller. With the help of these colleagues I am confident that the Journal will maintain the standard set by our predecessors, assess the increasing number of incoming papers fairly and above all help the reader encompass the explosive expansion of information about neuroscientific research. This will only be possible with the continued support of our editorial committee and the many neuroscientists in the United Kingdom and abroad who accept the task of refereeing papers submitted to the Journal. Without their freely given advice the system of peer review would not work. An editor cannot thank them enough.

The middle of a volume is not the time to make alterations but the editorial committee must soon decide what course to pursue in the face of the winds of change which blow in the medical publishing world. ${ }^{1}$ There is pressure to conform to modern styles by assuming the A4 format. This may be desirable because our present issues have grown so thick that binding a whole year into a single volume is becoming difficult. The larger A4 format would also give us more freedom in designing the display of illustrations and photographs. The Journal has not been in the habit of publishing editorials. Maybe this should change. Readers would probably appreciate carefully selected or solicited, succinct authoritative statements about advances in research and controversies in practice. The number of biomedical and scientific journals published worldwide, already 120,000 , is increasing by $5-7 \%$ a year. The proliferation of journals within neuroscientific sub-specialties is inevitable as new fields emerge but the right place for publishing significant advances which have an impact on the whole neuroscientific field is in a general neurological journal such as ours. This applies as much to the non-clinical as the clinical specialties. Whatever his sub-specialty each author must make his or her meaning clear to colleagues in related disciplines. The editor will take refuge in the thought that what he cannot understand other readers may find similarly difficult. One final thought is that although the Journal is international in the source of its papers, in the distribution of its readers and in its scientific outlook, its editorial committee is largely British. Modern communications should make it easier for us to obtain advice from beyond the shores of our sceptred isle.

\section{Reference}

1 Medvei VC. Wind of change. II. Medical journals in Britain in 1988. J R Soc Med 1988;81:686-8. 